\title{
Application of Excel in the Operation Management of the Group Company
}

\author{
Hongxiao Zhou ${ }^{1, a^{*}}$, Weifu Tian ${ }^{2, b}$ \\ ${ }^{1}$ Jinhua Polytechnic, Jinhua Zhejiang China, 321007 \\ ${ }^{2}$ Zhejiang Normal University, Jinhua Zhejiang China, 321004 \\ aizhx@qq.com, ${ }^{\text {itwf@zjnu.cn }}$
}

Keywords: Excel 2010, Mathematical Model, Linear Regression, Solver, the Optimization Problems Abstract. In the operation management of the group company, we often need make decisions about production, manufacturing, transportation, investment and other programs based on the group's profit maximization. In other words, we often need solve optimization problems such as maximum profit, minimum cost, etc.. In the manual state, the graphical method and the simplex method are usually used to solve this kind of problem. But the graphical method is not accurate enough, and the simplex method is very complicated. Through an example, the paper introduces the application of Excel function and solver tool in the decision-making about production and transportation programs. The modeling ideas and solving methods can be generalized to other decision-making problem about maximum profit or minimum cost. This will help improve greatly the company's decision-making efficiency.

\section{Introduction}

Group company management involves the production, transportation, sales and other links. In order to maximize the group's profit, many problems should be solved such as where to produce, how much to produce, where to sell, etc. In decision-making about the plan of production and transportation of the next year, the traditional graphic method is not accurate enough; the simplex method is quite complicated. Excel linear regression prediction function can be used to predict quickly the production cost based on historical data; and Excel solver tool can be used to find quickly the optimal solution. This method can help to improve production organization and enhance the efficiency of corporate decision-making; moreover, it can help to promote financial officers more involved in management decisions $^{[1]}$.

\section{Problem Description}

A group company has 4 factories; the products are sold to 5 cities named A, B, C, D and E. The demands of the 5 cities in 2015 are 1100000 tons, 1600000 tons, 800000 tons, 2000000 tons and 1000000 tons. Resource consumption coefficient is 2.5. The transportation cost per ton is shown in Table 1. Table 2 provides some production data of the 4 factories, and Table 3 provides the production cost per ton for the last ten years. (Note: resource consumption coefficient is the number of resources required for a unit of production).In the case of ensuring the completion of the market demand, the group management hopes that the financial department will make a production and transportation plan to maximize the group's profit in 2015.

Table 1 Transportation Cost (Yuan Per Ton)

\begin{tabular}{|l|c|c|c|c|c|}
\hline & City A & City B & City C & City D & City E \\
\hline Factory 1 & 80 & 130 & 120 & 30 & 140 \\
\hline Factory 2 & 100 & 60 & 70 & 30 & 90 \\
\hline Factory 3 & 40 & 90 & 60 & 50 & 40 \\
\hline Factory 4 & 70 & 50 & 90 & 120 & 100 \\
\hline
\end{tabular}


Table 2 Factory Production Data

\begin{tabular}{|l|c|c|c|}
\hline & $\begin{array}{c}\text { Annual Production } \\
\text { Capacity (Ton) }\end{array}$ & $\begin{array}{c}\text { Additional Investments } \\
\text { Beyond the Capacity }\end{array}$ & $\begin{array}{c}\text { Resource Limitation } \\
\text { (Ton) }\end{array}$ \\
\hline Factory 1 & 1000000 & 1.4 & 5000000 \\
\hline Factory 2 & 1500000 & 0.8 & 8000000 \\
\hline Factory 3 & 1200000 & 1.1 & 6000000 \\
\hline Factory 4 & 1300000 & 1.5 & 7000000 \\
\hline
\end{tabular}

Table 3 Production Cost (Million Yuan Per Ton)

\begin{tabular}{|c|c|c|c|c|}
\hline Year & Factory 1 & Factory 2 & Factory 3 & Factory 4 \\
\hline 2014 & 1.123 & 1.169 & 0.9 & 1.244 \\
\hline 2013 & 1.096 & 0.989 & 0.95 & 1.05 \\
\hline 2012 & 1.037 & 0.97 & 0.935 & 1.065 \\
\hline 2011 & 0.995 & 0.959 & 0.92 & 1.024 \\
\hline 2010 & 0.99 & 0.953 & 0.9 & 1.022 \\
\hline 2009 & 0.96 & 0.925 & 0.857 & 0.98 \\
\hline 2008 & 0.936 & 0.758 & 0.815 & 0.899 \\
\hline 2007 & 0.882 & 0.744 & 0.705 & 0.892 \\
\hline 2006 & 0.877 & 0.66 & 0.688 & 0.764 \\
\hline 2005 & 0.843 & 0.622 & 0.684 & 0.721 \\
\hline
\end{tabular}

\section{Problem Analysis}

Since production cost in the last ten years is given, we can use linear prediction function in Excel to predict the unit production cost in 2015. The transportation cost from each factory to each city is different; and the production cost of each factory is also different; additional investment required for 1 ton production beyond annual production capacity is also not the same, so we need to set two kinds of decision variables, they are product quantities transported to the city within annual production capacity and beyond annual production capacity.

The 2015 production and transportation plan based on the group's maximum profit is to find out products quantities transported to various cities within the annual production capacity and beyond annual production capacity while the sum of transportation costs and production costs reaches the minimum.

\section{Establishment of Linear Mathematical Model}

Model Hypothesis. A model is established by products quantities transported to various cities and the constraints of minimizing the cost.

Symbol Description.A1, A2, A3 and A4 represent four factories, B1, B2, B3, B4, B5 represent five cities. $\mathrm{Xij}$ are products quantities transported to various cities from each factory within the annual capacity, Yij are products quantities transported to various cities from each factory beyond the annual capacity $(i=1,2,3,4 ; j=1,3,4,5)$. W1, W2, W3, W4 represent the factory's unit production costs in 2015 (million yuan per ton). Set the total cost of production in 2015 is $Y$, the total cost of transportation is $\mathrm{Z}$, the total cost is $\mathrm{M}$, then $\mathrm{M}=\mathrm{Y}+\mathrm{Z}$. The goal is to find out $\mathrm{Xij}$ and $\mathrm{Yij}$, which make $M$ reach the minimum value.

Establishment of the Model. In Excel, the maximum output of 4 factories can be obtained quickly by the resource consumption coefficient, resource limitation and annual production capacity. The results are shown in Table 4. The decision-making variables and various known conditions are sorted into Table 5.

Table 4 Maximum Output beyond Production Capacity (Ton)

\begin{tabular}{|c|c|c|c|c|}
\hline Factory & $\begin{array}{c}\text { Resource } \\
\text { Limitation }\end{array}$ & $\begin{array}{c}\text { the Maximum } \\
\text { Output }\end{array}$ & $\begin{array}{c}\text { Production } \\
\text { Capacity }\end{array}$ & $\begin{array}{c}\text { the Maximum Output beyond } \\
\text { Production Capacity }\end{array}$ \\
\hline A1 & 5000000 & 2000000 & 1000000 & 1000000 \\
\hline A2 & 8000000 & 3200000 & 1500000 & 1700000 \\
\hline A3 & 6000000 & 2400000 & 1200000 & 1200000 \\
\hline A4 & 7000000 & 2800000 & 1300000 & 1500000 \\
\hline
\end{tabular}


Table 5 Decision Variables and Constraint Conditions

\begin{tabular}{|c|c|c|c|c|c|c|}
\hline \multicolumn{6}{|c|}{ Product Quantities Transported to Various Cities from Each Factory within the Annual Production Capacity } & \multirow[b]{2}{*}{ Production Capacity } \\
\hline & B1 & B2 & B3 & B4 & B5 & \\
\hline A1 & $\mathrm{X} 11$ & $\mathrm{X} 12$ & $\mathrm{X} 13$ & $\mathrm{X} 14$ & $\mathrm{X} 15$ & 1000000 \\
\hline $\mathrm{A} 2$ & $\mathrm{X} 21$ & $\mathrm{X} 22$ & $\mathrm{X} 23$ & $\mathrm{X} 24$ & $\mathrm{X} 25$ & 1500000 \\
\hline A3 & $\mathrm{X} 31$ & $\mathrm{X} 32$ & $\mathrm{X} 33$ & $\mathrm{X} 34$ & $\mathrm{X} 35$ & 1200000 \\
\hline A4 & $\mathrm{X} 41$ & $\mathrm{X} 42$ & $\mathrm{X} 43$ & $\mathrm{X} 44$ & $\mathrm{X} 45$ & 1300000 \\
\hline \multicolumn{6}{|c|}{ Product Quantities Transported to Various Cities from Each Factory beyond the Annual Production Capacity } & Resource Limitation \\
\hline $\mathrm{A} 1$ & Y11 & Y12 & $\mathrm{Y} 13$ & Y14 & Y15 & 1000000 \\
\hline $\mathrm{A} 2$ & $\mathrm{Y} 21$ & $\mathrm{Y} 22$ & $\mathrm{Y} 23$ & $\mathrm{Y} 24$ & Y25 & 1700000 \\
\hline $\mathrm{A} 3$ & Y31 & Y32 & Y33 & Y34 & Y35 & 1200000 \\
\hline $\mathrm{A} 4$ & Y41 & Y42 & Y43 & Y44 & $\mathrm{Y} 45$ & 1500000 \\
\hline Products Demand & 1100000 & 1600000 & 800000 & 2000000 & 1000000 & \\
\hline
\end{tabular}

Table 6 Production Costs within the Capacity and beyond the Capacity

\begin{tabular}{|c|c|c|c|}
\hline Factory & Production Costs within the Capacity & $\begin{array}{c}\text { Additional Investments beyond the Capacity } \\
\text { (Million Yuan Per Ton) }\end{array}$ & $\begin{array}{c}\text { Production Costs beyond the Capacity } \\
\text { (Million Yuan Per Ton) }\end{array}$ \\
\hline A1 & W1 & 1.4 & W1+1.4 \\
\hline A2 & W2 & 0.8 & W2 +0.8 \\
\hline A3 & W3 & 1.1 & W3+1.1 \\
\hline A4 & W4 & 1.5 & W4+1.5 \\
\hline
\end{tabular}

Table 7 Transportation Cost per Ton of Goods (Unit: Million Yuan)

\begin{tabular}{|c|c|c|c|c|c|}
\hline & B1 & B2 & B3 & B4 & B5 \\
\hline A1 & 0.008 & 0.013 & 0.012 & 0.003 & 0.014 \\
\hline A2 & 0.01 & 0.006 & 0.007 & 0.003 & 0.009 \\
\hline A3 & 0.004 & 0.009 & 0.006 & 0.005 & 0.004 \\
\hline A4 & 0.007 & 0.005 & 0.009 & 0.012 & 0.01 \\
\hline
\end{tabular}

Objective function: $\min \mathrm{M}=\mathrm{Y}+\mathrm{Z}$

Constraints 1, products meet the needs of the city:

$\sum_{i=1}^{4}(X i 1+Y i 1)=1100000, \sum_{i=1}^{4}(X i 2+Y i 2)=1600000, \sum_{i=1}^{4}(X i 3+Y i 3)=800000$,

$\sum_{i=1}^{4}(X i 4+Y i 4)=2000000, \sum_{i=1}^{4}(X i 5+Y i 5)=1000000$

Constraints 2, production capacity constraints:

$\sum_{i=1}^{5} x 1 j \leq 1000000, \sum_{j=1}^{5} x 2 j \leq 1500000, \sum^{5} x 3 j \leq 1200000, \sum^{5} x 4 j \leq 1300000$

Constraints 3, resource limitation constraints:

$\sum^{5} \mathrm{Y} 1 \mathrm{j} \leq 1000000, \sum^{5} \mathrm{Y} 2 \mathrm{j} \leq 1700000, \sum^{5} \mathrm{Y} 3 \mathrm{j} \leq 1200000, \sum^{5} \mathrm{Y} 4 \mathrm{j} \leq 1500000$

Constraints 4, non-negative constraints: $X i j \geq 0, Y i j \geq 0$

\section{Solution in Excel}

Establish a Model for Solving the Problem In Excel. Enter the group's decision data into the new Excel table; establish the solver model as shown in Fig. 1. The shadow part is the variables of the model, that is, the production and transportation scheme for each factory. As shown in Fig. 1, input formula in Cell G3:G6, G9:G12 and B14:F14, formula result represents the output of each factory within the capacity, the output of each factory beyond the capacity, and products quantities transported to various cities.

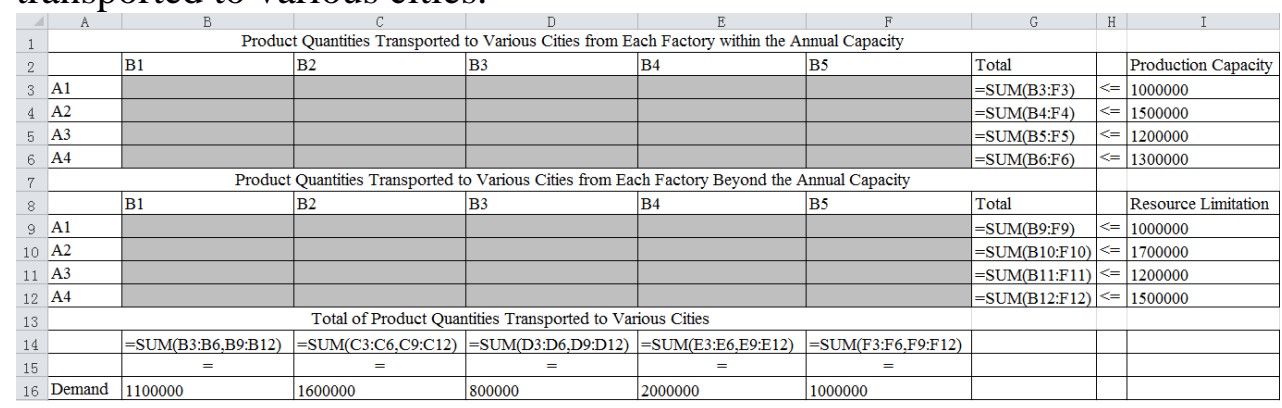

Fig. 1 the Variable Cells and Constraint Conditions of Solver 
According to the production cost data from 2005 to 2014, the excel linear regression forecasting function is used to forecast the production cost of each factory in 2015, and the calculation method is shown in Fig. 2. Among them, B21:K24 display the factory's unit production costs from 2005 to 2014, cells L21:L24 use the forecast function to calculate the cost of production in 2015, the specific formula is shown in Fig. 2. The function FORECAST is to calculate or predict the future value according to the given data ${ }^{[2]}$.

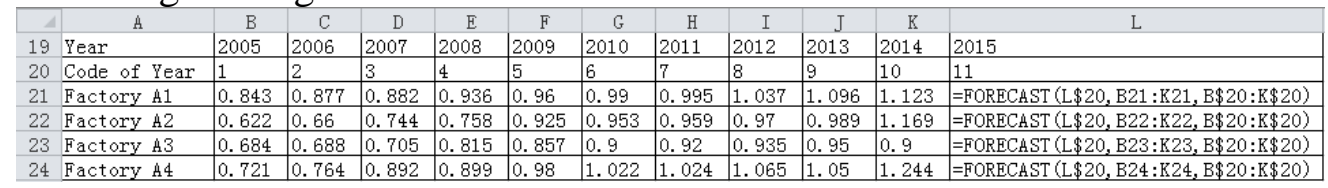

Fig. 2 Production Cost Forecast in 2015

According to the production cost calculated in Fig.2 and the additional investment required, calculate the unit production cost of each factory beyond the capacity.For the convenience of calculation, unit production costs within the capacity, unit production costs beyond the capacity and unit transportation costs are designed to be a 4 x 5 table, as shown in Fig.3.

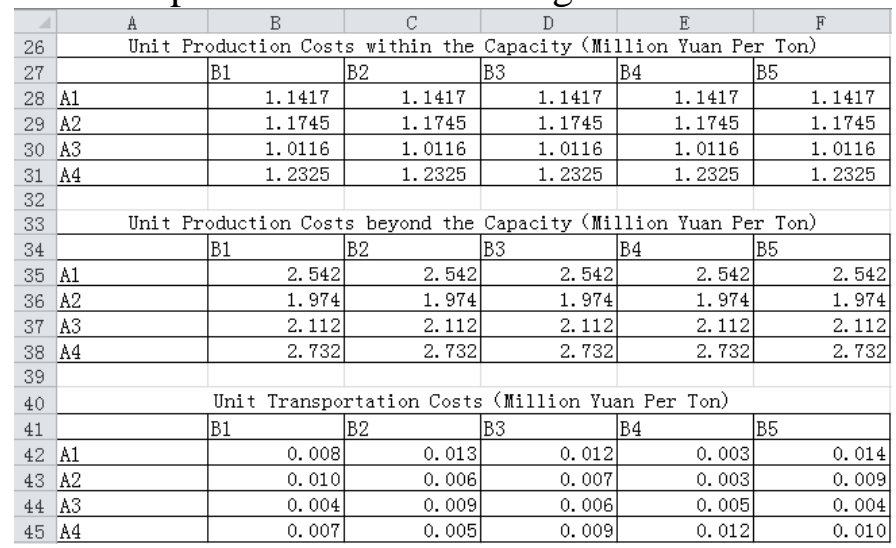

Fig. 3 Unit Production Costs and Transportation Costs

\begin{tabular}{|c|c|c|c|}
\hline & A & & B \\
\hline 48 & Production Costs within the Capacity & (Million Yuan) & $=$ =SUMPRODUCT(B28:F31,B3:F6) \\
\hline 49 & Production Costs beyond the Capac & $y$ (Million Yuan) & $=$ SUMPRODUCT(B35:F38,B9:F12) \\
\hline 50 & Production Costs(Million Yuan) & $\mathrm{Y}$ & $=$ SUM(B48:B49) \\
\hline 51 & Transportation Costs(Million Yuan) & $\mathrm{Z}$ & $=$ SUMPRODUCT(B3:F6+B9:F12,B42:F45) \\
\hline 52 & Total Costs(Million Yuan) & $\mathrm{M}$ & $=\mathrm{SUM}(\mathrm{B} 50: \mathrm{B} 51)$ \\
\hline
\end{tabular}

Fig. 4 Objective Function of the Model

Using the function SUMPRODUCT ${ }^{[3]}$ to calculate production costs within the capacity, production costs beyond the capacity and the total transportation cost. We get the value of $\mathrm{Y}, \mathrm{Z}$ and $\mathrm{M}$, the specific formula is shown in Fig. 4. Y, Z and $\mathrm{M}$ are respectively corresponding to cell B50, B51, B52 in Fig 4. The function SUMPRODUCT is to multiply the form data with the same dimension, and return the sum of these products.

Planning Solution.Solver is an additional function in Excel 2010, and it needs to be added in before the first use. The specific method of adding-in is as follows: under the tab "File", select tab "Options"; open the dialog box "Excel Options", under the tab "Add Ins", click the button "Go To", open the dialog box "Add-Ins", select the check box "Solver Add-in", click "OK" button to complete adding-in.

Open the solver tool, the dialog box "Parameters of Solver". Set the cell B52 for the target, select the option "Minimum Value". Variable cells are shaded in Fig. 1, that is, \$B \$3:\$F\$6, \$B \$9:\$F\$12. Add in the first 3 constraints in the model, namely $\$ B \$ 14: \$ F \$ 14=\$ B \$ 16: \$ F \$ 16$ (Order Demands),

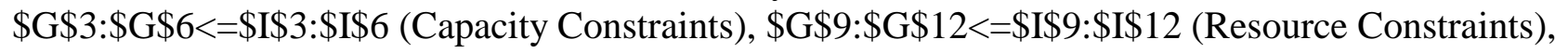
select the check box "Non-negative Variables", which is equivalent to the fourth constraints in the model.

Select "Simplex Linear Programming" as method for solving. Click the "Solve" button, display a dialog box, click "OK", a solution is found (shown in Table 8 and Table 9), which can satisfy all the constraints and optimal conditions. From Table 8 we can see that the minimum total cost is 
87131600000 yuan. From Table 9 the optimum production and transportation scheme is shown in Table 10. 1000000 tons of products will be produced in Factory 1, all of them will be transported to City D; 3000000 tons of products will be produced in Factory 2, 1200000 tons of them will be transported to City B,800000 tons of them will be transported to City C, 1000000 tons of them will be transported to City D; 1200000 tons of products will be produced in Factory 3 , 200000 tons of them will be transported to City A, 1000000 tons of them will be transported to City E; 1300000 tons of products will be produced in Factory 4, 900000 tons of them will be transported to City A,400000 tons of them will be transported to City B. In the scheme, only the output of Factory 2 is beyond its annual capacity.

Table 8 Results of the Solver - the Minimum Total Cost

\begin{tabular}{|c|c|}
\hline Production Costs Within The Capacity(Million Yuan) & 5719560 \\
\hline Production Costs Beyond The Capacity(Million Yuan) & 2961700 \\
\hline Production Costs(Million Yuan) $\quad \mathrm{Y}$ & 8681260 \\
\hline Transportation Costs(Million Yuan) Z & 31900 \\
\hline Total Costs(Million Yuan) & 8713160 \\
\hline
\end{tabular}

Table 9 Results of the Solver - Production and Transportation Scheme

\begin{tabular}{|c|c|c|c|c|c|c|}
\hline \multicolumn{7}{|c|}{ Product Quantities Transported to Various Cities from Each Factory within the Annual Capacity } \\
\hline & B1 & B2 & B3 & B4 & B5 & Total \\
\hline $\mathrm{A} 1$ & 0 & 0 & 0 & 1000000 & 0 & 1000000 \\
\hline $\mathrm{A} 2$ & 0 & 0 & 500000 & 1000000 & 0 & 1500000 \\
\hline A3 & 200000 & 0 & 0 & 0 & 1000000 & 1200000 \\
\hline $\mathrm{A} 4$ & 900000 & 400000 & 0 & 0 & 0 & 1300000 \\
\hline \multicolumn{7}{|c|}{ Product Quantities Transported to Various Cities from Each Factory beyond the Annual Capacity } \\
\hline & B1 & B2 & B3 & B4 & B5 & Total \\
\hline $\mathrm{A} 1$ & 0 & 0 & 0 & 0 & 0 & 0 \\
\hline $\mathrm{A} 2$ & 0 & 1200000 & 300000 & 0 & 0 & 1500000 \\
\hline A3 & 0 & 0 & 0 & 0 & 0 & 0 \\
\hline $\mathrm{A} 4$ & 0 & 0 & 0 & 0 & 0 & 0 \\
\hline
\end{tabular}

Table 10 Production and Transportation Scheme (Ton)

\begin{tabular}{|c|c|c|c|c|c|c|}
\hline & Output & City A & City B & City C & City D & City E \\
\hline Factory 1 & 1000000 & 0 & 0 & 0 & 1000000 & 0 \\
\hline Factory 2 & 3000000 & 0 & 1200000 & 800000 & 1000000 & 0 \\
\hline Factory 3 & 1200000 & 200000 & 0 & 0 & 0 & 1000000 \\
\hline Factory 4 & 1300000 & 900000 & 400000 & 0 & 0 & 0 \\
\hline
\end{tabular}

\section{Conclusion}

After the establishment of the model, if the original data changes, such as the order of production, production capacity, resource constraints and other changes, we only do a little adjustment of the original data in the Excel table. When the number of factories and cities changes, only some changes are needed in the model.Therefore, the model can be applied flexibly in all production transportation optimization schemes, and it is beneficial to improve the enterprise production organization and plan management.

In the management of the company, the decision-making problem about the maximum profit or the minimum cost can be solved rapidly by solver tool in Excel. This will help improve greatly the company's decision-making efficiency.

\section{References}

[1] Bin Fan, Zhijian Zhao, the Basis of Accounting Information - Excel Advanced Application, People's Posts and Telecom Press, Beijing, 2008.

[2] Excel Home, the Essence of Data Processing and Analysis Combat Skills, People's Posts and Telecom Press, Beijing, 2008.

[3] Information on http://www.excelhome.net 